\title{
Vaccination Policies of Utah Family Practice Clinics
}

\author{
Karlen Beth Luthy \\ Brigham Young University - Provo, beth-luthy@byu.edu \\ Levi R. Kohler \\ Janelle L B Macintosh \\ $B Y U$ \\ Lacey M. Eden \\ BYU \\ Renea L. Beckstrand \\ Brigham Young University - Provo

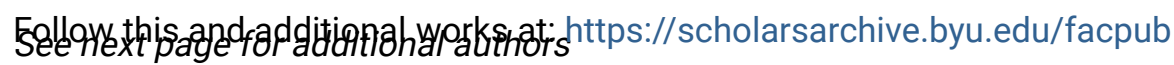 \\ Part of the Nursing Commons
}

\section{Original Publication Citation}

Luthy, K.E., Kohler, L.R., Macintosh, J.L.B., Eden, L.M., Beckstrand, R.L., Wright, E.L., Hill, K.E. (2016) Vaccination policies of Utah family practice clinics. Journal of the American Association of Nurse Practitioners, . Article in Press. doi: 10.1002/2327-6924.12395

\section{BYU ScholarsArchive Citation}

Luthy, Karlen Beth; Kohler, Levi R.; Macintosh, Janelle L B; Eden, Lacey M.; Beckstrand, Renea L.; Wright, Emily L.; and Edmonds, Katherine, "Vaccination Policies of Utah Family Practice Clinics" (2016). Faculty Publications. 1791.

https://scholarsarchive.byu.edu/facpub/1791

This Peer-Reviewed Article is brought to you for free and open access by BYU ScholarsArchive. It has been accepted for inclusion in Faculty Publications by an authorized administrator of BYU ScholarsArchive. For more information, please contact ellen_amatangelo@byu.edu. 


\section{Authors}

Karlen Beth Luthy, Levi R. Kohler, Janelle L B Macintosh, Lacey M. Eden, Renea L. Beckstrand, Emily L. Wright, and Katherine Edmonds 
Vaccination Policies of Utah Family Practice Clinics

\section{CONTACT AUTHOR}

Karlen E. Luthy, DNP, FNP-c, Associate Professor

College of Nursing, Brigham Young University

457 SWKT

Provo, UT 84602

801-422-6683 Office

801-422-0536 Fax

beth_luthy@byu.edu

Levi R. Kohler, BS, RN, Graduate Student

College of Nursing, Brigham Young University

Janelle L. B. Macintosh, PhD, RN, Assistant Professor

College of Nursing, Brigham Young University

Lacey M. Eden, MS, FNP-c, Assistant Teaching Professor

College of Nursing, Brigham Young University

Renea L. Beckstrand, PhD, RN, CCRN, CNE, Professor

College of Nursing, Brigham Young University

Emily L. Wright, BS, RN

College of Nursing, Brigham Young University

Katherine Edmonds, BS, RN

Thyroid Institute of Utah 


\begin{abstract}
Background and Purpose: The purpose of this study was to collect information regarding healthcare worker $(\mathrm{HCW})$ vaccination policies in Utah family practice clinics.

Methods: The study was conducted in Utah family practice clinics in the most densely populated counties in the state and was a cross-sectional descriptive design. Data were collected from 155 family practice clinic managers. Analyses included frequencies and percentages for quantitative items and a content analysis for open-ended items.

Conclusions: HCWs are employed in environments where infectious diseases can be easily spread from person to person, thus, vaccinations can be instrumental in protecting the health of HCWs and patients alike. In Utah, $56.8 \%$ of family practice clinics had either no vaccination policy for HCWs or had a policy with no consequences for noncompliance. Utah family practice clinics need to implement changes to create and maintain HCW vaccination policies.

Implications for Practice: Nurse practitioners can be leaders and change agents by working with their county and state health departments to create state-wide policies that mirror the position statements from the American Nurses Association and the American Association of Nurse Practitioners.
\end{abstract}


Vaccine-preventable diseases such as influenza, measles, and pertussis are on the rise in the United States (Lea, 2011), an issue that can be attributed to waning vaccination rates in American communities (Constable, Blank, \& Caplan, 2014). As a result, every year more than 200,000 Americans are hospitalized for complications related to influenza (United States Department of Health and Human Services, 2014). Similarly, even though a safe and effective measles vaccination is available, there were 668 cases of measles reported in the United States in 2014, the highest number of cases in the last two decades (Centers for Disease Control and Prevention [CDC], 2014a). Additionally, cases of pertussis continue to increase (Debolt et al., 2012), a worrisome statistic considering the disease causes death, especially in infants under 3 months of age (CDC, 2014b).

Vaccines are routinely recommended for children, although the need for vaccines continues beyond childhood and into adulthood (CDC, 2014c). However, adult vaccination recommendations differ depending on the adult's age, lifestyle, co-morbidities, travel history, and previously documented vaccinations (CDC, 2012). Notwithstanding the potential variations in the recommended adult vaccination schedule, some vaccines are routinely recommended for the majority of adults including: 1) a measles, mumps, and rubella (MMR) vaccination as an adult (Immunization Action Coalition [IAC], 2014a); 2) a seasonal influenza vaccination every year (CDC, 2013a); 3) a tetanus vaccination every 10 years (CDC, 2013b); and 4) a one-time dose of pertussis in adulthood (CDC, 2013b).

As adults who are at-risk for contracting and spreading communicable diseases among co-workers and patients, it is especially important for healthcare workers (HCWs) to be fully vaccinated. In 2015, the Advisory Committee on Immunization Practices (ACIP) updated the vaccine recommendations for $\mathrm{HCWs}(\mathrm{CDC}, 2015)$. The updated $\mathrm{HCW}$ vaccination guidelines 
now include recommendations for two MMR, a seasonal influenza, one pertussis, two varicella, and three Hepatitis B (IAC, 2014b). Healthy People 2020 (2016) goals regarding HCW vaccination rates are identical for Hepatitis B and influenza at 90\%. Despite the ACIP recommendations and Healthy People 2020 goals, however, HCW vaccination rates are only $68 \%$ for Hepatitis B and $80 \%$ for influenza. No data are available on HCW vaccination for MMR and varicella, and pertussis vaccination rates among HCWs are reported to be suboptimal (CDC, 2011). Currently, there are no HCW vaccination benchmarks for MMR, pertussis, and varicella. Vaccination recommendations for Utah HCWs follow the Immunization Action Coalition guidelines (Utah Department of Health [UDOH], 2010a). Since 2007, vaccination rates of hospital-based HCWs in Utah has been consistently higher than the national average (UDOH, 2010b). For example, in $201063.5 \%$ of HCWs employed in the hospital setting were up-to-date on the influenza vaccine. In comparison, $82.7 \%$ of hospital HCWs in Utah were up-to-date on the influenza vaccine during the same time period (UDOH, 2010b).

While data are available on HCW vaccination rates in Utah hospital-based facilities, the vaccination status of Utah outpatient HCWs is unknown. However, similar to hospital-based environments, HCWs employed in outpatient facilities also come into daily contact with patients. In the family practice setting, each healthcare provider spends about 34 hours of each work week in face-to-face contact with patients, accounting for approximately 89 patient encounters every week (American Academy of Family Physicians, 2011). Because some patients may be especially vulnerable to vaccine-preventable diseases, such as infants, the elderly, and immunocompromised (Infectious Diseases Society of America [IDSA], 2014), it is important for HCWs in the family practice setting to be fully vaccinated. 
Vaccination policies play an important role in safeguarding the health of HCWs and patients. The Healthcare Infection Control Practices Advisory Committee encourages all healthcare facilities, whether in-patient or out-patient, to create and maintain a HCW vaccination policy (CDC, 2011). As the vaccine policy gatekeepers and record keepers, facility managers shoulder the majority of responsibility when it comes to ensuring all HCWs are up-to-date with vaccinations as recommended by the ACIP. Ideally, office managers should evaluate HCW vaccination status at the time of hire and on an annual basis (CDC, 2011). In addition, organizations such as the Infectious Diseases Society of America, the Pediatric Infectious Diseases Society, and the Society for Healthcare Epidemiology of America (2013) support mandatory $\mathrm{HCW}$ vaccination as a condition of employment. However, the presence of vaccination policies in the out-patient clinic setting and the consequences for HCW noncompliance was largely unknown in Utah. Thus, the purpose of this study was to describe vaccination policies of HCWs in Utah family practice clinics.

\section{Research Questions}

1) How do managers of Utah family practice clinics describe their $\mathrm{HCW}$ vaccination policies?

2) What are the consequences regarding HCW non-compliance of vaccination policies Utah family practice clinics?

\section{Methods}

\section{Participants}

Approval from the Institutional Review Board was granted prior to the collection of data. Informed consent was obtained from the participants. The sample included clinic managers from 155 Utah family practice clinics located in the most densely populated counties in Utah: Davis, Weber, Salt Lake, Utah, and Washington (United States Census Bureau, 2010). A list of family 
practice clinics in these counties was generated from an online search and healthcare provider information from local insurance companies (SelectHealth, Altius, Blue Cross Blue Shield). Clinic lists were cross-checked to avoid redundancies. To be eligible for participation, clinic managers needed to be employed either part-time or full-time in a family practice clinic in a densely populated county in Utah.

\section{Setting}

The study took place in Utah, the $33^{\text {rd }}$ most populous state in the country. While most of the Utah land mass is rural, $89 \%$ of the population lives in urban areas. Additionally, $37 \%$ of Utah's total population reside in Salt Lake County. While Utah is one of the less populated states, it had the third fastest population growth rate between 2010 and 2012 (Henry J. Kaiser Family Foundation, 2014).

\section{Design}

This study was a cross-sectional, descriptive design. The managers of Utah family practice clinics located in the most densely populated counties were initially contacted by phone to explain the study and eligibility requirements. After the initial phone call, the clinic managers received a packet that included the informed consent document, the study questionnaire, an addressed and stamped return envelope, and $\$ 1.00$ incentive for participation. Four weeks after the initial mailing, a follow-up packet was mailed to all non-responders, although the cash incentive was not included in the second mailing.

\section{Instrument}

The original instrument was designed by a group of researchers from Utah and was reviewed by a panel of Utah health experts, including local and state health department employees, healthcare providers, and vaccination experts, thereby establishing content validity. 
The original questionnaire was pre-tested in 12 outpatient clinics, including family and primary care clinics, and then adjusted according to feedback. The questionnaire was also utilized in another study involving pediatric clinics (Luthy et al., 2016) and was adjusted for the family practice environment. The questionnaire consists of six demographic, eight multiple choice and four open-ended items.

Demographic questions addressed the participants' (clinic manager) age, gender, and years worked at the clinic as manager. Also included were questions about the clinic, including whether it was located in an urban, suburban, or rural area, the average number of patients seen per day, and percentage of clinic employees working directly with patients during a routine work day.

Multiple-choice questions addressed clinic policies and procedures for vaccination of various employees (i.e. front/back office staff, in-house billing staff, support staff, and administrators). If employees were able to refuse vaccinations despite the presence of a clinic vaccination policy, clinic managers were asked to select the response that most closely resembled the circumstances under which refusals were allowed. Because it was possible that the clinic manager was newly appointed and may not be familiar with the clinic vaccination policy or how to navigate a HCW's refusal of vaccines, they were allowed to select an "I don't know" option. Clinic managers were also asked about the availability of the required vaccines and if the clinic offered the vaccines free of charge to employees. All multiple-choice questions also contained an "other" choice to allow the clinic manager to write in their own response.

The questionnaire concluded with four open-ended questions. These included questions on how long the employee vaccination policy was in effect, how often employee vaccination records were reviewed, and common barriers clinic managers faced with regard to the 
vaccination policies. There was also a space provided for clinic managers to provide any additional comments regarding their clinic's vaccination policy.

\section{Data Analysis}

Responses were entered into SPSS 21 (SPSS Inc., Chicago IL, 2012). After the data were entered, two separate researchers checked the data for accuracy. The primary investigator examined the items when there was a question regarding a marked response and determined the correct response. Descriptive statistics were performed to include frequencies and percentages as well as content analysis for open-ended items. Both quantitative and qualitative results are reported.

\section{Results}

Of the 155 questionnaires mailed to Utah family practice clinics in Davis, Weber, Salt Lake, Utah, and Washington counties, 91 were returned for a response rate of $59 \%$. The mean age of the clinic managers was 47 years $(\mathrm{SD}=11.5)$. The average number of years the office manager worked at the facility was 11.2 years $(\mathrm{SD}=8.1)$.

Demographic data were also collected on the family practice clinics. Of the responding managers, 34 clinics $(46.6 \%)$ were located in a suburban setting, $32(43.8 \%)$ were located in an urban setting, and $7(9.6 \%)$ located in a rural setting. The average number of patients served in the clinic per day, not including on-call or hospitalized patients, was $113.7(\mathrm{SD}=153.9)$ (see Table 1).

\section{Vaccine Policy Description}

Participants were asked to select the response that best described their facility's vaccination policy. Of the 81 who responded, 30 (37.0\%) managers stated vaccinations for employees were recommended, although employees were also allowed to refuse vaccinations 
without consequence, and 19 (23.5\%) reported that employee vaccinations were mandated, although refusal to comply with the vaccination policy resulted in consequences other than termination. Sixteen (19.8\%) managers stated the clinic had no official vaccination policy. Only $18.5 \%(\mathrm{n}=15)$ of managers reported that employee refusal of policy resulted in termination. One manager (1.2\%) selected the "other" option.

Clinic managers were also asked to report which vaccines were included in the clinic's policy. Influenza was the most commonly selected response $(\mathrm{n}=52,57 \%)$, with forty-eight (52.7\%) managers including hepatitis B in their vaccination policy. Tdap was included as part of the vaccination policy $37.4 \%(\mathrm{n}=34)$ of the time. There were $29(31.9 \%)$ managers who reported the clinic vaccination policy included Hepatitis A. Additionally, 23 (25.3\%) clinic managers reported that MMR (or proof of the disease) was included as part of the vaccination policy and $16(17.6 \%)$ managers reported that the vaccination policy included varicella (or proof of the disease).

Clinic managers were also asked to specify the employees to whom the clinic's vaccination policy applied. Employees working in the back office (i.e. clinicians, medical assistants, and nurses) were selected most frequently $(\mathrm{n}=61,67 \%)$. Receptionists, schedulers, and other employees working in the front office were the next most commonly selected group $(\mathrm{n}=53,58.2 \%)$. Clinic managers and administrative staff were subject to the vaccination policy 49.5\% $(n=45)$ of the time. Clinic managers also reported that in-house billing staff $(n=36$, $39.6 \%)$ and support staff such as custodians and IT support $(n=29,31.9 \%)$ were subject to the vaccination policy less frequently. Ten (11\%) clinic managers reported that the vaccine policy applied to "other" employees. 
The clinic managers were asked when their current policy was implemented and how often the employee vaccination records were reviewed. Twenty-four (92.4\%) managers reported that the employee vaccination policy had been implemented within the last 15 years. However, $36(58.1 \%)$ managers were unsure of the year the vaccination policy was implemented. When questioned about the frequency with which employee vaccination records were reviewed, $62.7 \%$ $(n=35)$ of clinic managers reported they reviewed the employee vaccination records every year.

\section{Employee Refusal of Vaccines}

Managers reporting that clinic employees could refuse vaccinations were asked to provide additional information about the refusal process. Vaccination refusals were allowed for medical reasons, as long as the employee had a written excuse from their healthcare provider (n $=35,38.5 \%)$. Another $38.5 \%(\mathrm{n}=35)$ allowed employees to refuse the clinic vaccination policy if the vaccination did not align with their religious beliefs. Managers also allowed employees to refuse vaccinations for medical reasons even though the medical contraindication was selfreported by the employee rather than a healthcare provider $(n=34,37.4 \%)$. Twenty-six $(28.6 \%)$ clinic managers reported employees could refuse vaccinations based on the employee's personal beliefs. Only $3(3.3 \%)$ managers reported that employees were not allowed to refuse vaccinations.

Additionally, clinic managers were asked to describe the accepted method of documentation for refusal of vaccines. Of the 63 who responded, the employee's vaccination refusal was formally documented on a paper form $(n=31,49.2 \%)$. Interestingly, $16(25.4 \%)$ managers either did not know how to document the employee's refusal of vaccines or reported that the employee vaccine refusal was not formally documented. Eight (12.7\%) managers reported that they informally documented the employee's vaccination refusal, 7 (11.1\%) 
managers formally documented the vaccination refusal on an electronic form, and $1(1.1 \%)$ manager selected the "other" response.

When asked about what items were required on the employee vaccination refusal form, the clinic managers were instructed to select all that apply. The most commonly selected answer was a hand or electronic signed statement by the employee $(n=25,27.5 \%)$. The second most common response was the inclusion of health risks to employees who refused vaccines for personal reasons $(\mathrm{n}=18,19.8 \%)$, followed closely by a statement of how refusal of employee vaccination poses a health risk to patients $(n=17,18.7 \%)$. Additionally, clinic managers included space for the employee to explain their rationale for refusing vaccines $(n=13,14.3 \%)$ and facility rationale for requiring the vaccine $(\mathrm{n}=12,13.2 \%)$. Only $5(5.5 \%)$ managers reported that they did not know what information was included on the vaccine refusal form.

Managers were also asked about the presence of additional restrictions for unvaccinated employees who arrived at work while ill. Twenty-one managers $(23.1 \%)$ required their unvaccinated and ill employees to wear masks if they had a fever, cough, or rash. Unvaccinated and ill employees were restricted from patient care duties $16.5 \%(n=15)$ of the time when they had a fever, cough, or rash. Interestingly, 22 (24.2\%) clinic managers reported there were no additional safety requirements for unvaccinated employees who reported to work while ill. Complete data presented in Table 2.

\section{Vaccine-related Services for Employees}

Clinic managers were asked to select all the vaccine-related services available for their employees. Clinics providing vaccinations free of charge to their employees was the most frequently selected response $(n=53,58.2 \%)$. Thirty-six $(39.6 \%)$ managers reported their employees were provided specific education regarding the benefits and risks of vaccinations. 
The third most commonly selected response was that employee vaccination rates were tracked on a regular basis $(n=27,29.7 \%)$. See Table 3 for complete data.

\section{Vaccine Policy Barriers}

Clinic managers were asked to provide an open-text response regarding the barriers they encountered to having a clinic vaccination policy. Thirty-six $(39.5 \%)$ responses were able to be coded into themes. The two main themes were problems with policy resistance and enforcement. The two minor themes included concern regarding violation of employee rights and limited resources.

Resistance to employee vaccination policies $(n=9,25 \%)$ and enforcement of the policies $(\mathrm{n}=9,25 \%)$ were the two most common themes. Managers expressed problems with employee resistance to the vaccination policy with comments such as, "Our doctor believes that vaccination is a personal choice. She does not believe all vaccinations are necessary for healthy adults," and "[There are issues with] the employees' willingness to do them." Managers also reported that enforcing the vaccination policy posed a challenge in comments such as, "[It's difficult to] keep track of vaccinations/employee medical records," and "[It's challenging to] remember to do it once a year."

Violation of employee rights, privacy and freedom $(n=4,11 \%)$ and unavailability of resources $(\mathrm{n}=4,11 \%)$ were also cited as formidable barriers to executing a clinic vaccination policy. Managers expressed concern regarding the potential violation of employee's rights, privacy, and freedom with comments such as, "Employees should be able to choose if they want vaccinations or not," and "[Vaccination policies] don't allow for employee choice. They feel forced to do something they may not want to do." The lack of resources was reported as a barrier to enforcing the clinic vaccination policy with comments such as, “... a small clinic like 
this one does not have resources to administer and enforce such a policy in terms of finances and manpower," and "The largest barrier for us is having a more inclusive vaccination policy is cost." Frequencies of all themes are reported on Table 4.

\section{Discussion}

HCWs are employed in an environment where they may regularly come into contact with infectious disease, thus, vaccinations are instrumental in protecting the health of HCWs (Infectious Diseases Society of America, 2015) and, by extension, those with whom HCWs have close contact beyond the work environment. Vaccinations not only benefit HCWs personally, but also protect the health and safety of the patients entrusted to their care. HCWs, therefore, have a professional and ethical responsibility to be fully vaccinated (Ottenberg et al., 2011; Theodoridou, 2014). However, not all institutions have HCW vaccination policies and even those who do may have policies with no real consequences for noncompliance. While most of the research thus far regarding $\mathrm{HCW}$ vaccinations has focused on the inpatient environment, the researchers of this Utah study found that managers in outpatient family practice clinics also struggle with ensuring full vaccination of all HCWs. In fact, most managers of Utah family practice clinics either had no vaccination policy for HCWs or had a vaccination policy with no consequences for noncompliance. Hence, it is necessary for family practice clinics to revisit existing $\mathrm{HCW}$ vaccination policies and to consider toughening consequences for noncompliance. Furthermore, family practice clinics with no $\mathrm{HCW}$ vaccination policy should institute a policy following the guidelines set forth by the ACIP.

Since 2009, the Centers for Disease Control and Prevention (CDC) have recommended the use of a mask by HCWs in healthcare settings to prevent the spread of influenza, particularly when the $\mathrm{HCW}$ or patient has a fever. However, the $\mathrm{CDC}$ also states that no studies have 
definitively proven that wearing a mask prevents the transmission of influenza from infectious patients or infectious HCWs (CDC, 2009). While vaccination remains the most effective tool in preventing the spread of infectious diseases (World Health Organization, 2015), many inpatient facilities still allow unvaccinated $\mathrm{HCW}$ s to continue working with the requirement of wearing a mask (Immunization Action Coalition, 2015). In our sample, few of the family practice clinics required unvaccinated $\mathrm{HCWs}$ who were ill to wear a mask while at work. Furthermore, it is concerning that less than one-fourth of managers in Utah family practice clinics had no additional requirements for unvaccinated employees who reported for work with an illness. Consequently, family practice clinic managers should reconsider $\mathrm{HCW}$ vaccination policies and implement more stringent vaccination policies. Rigorous influenza vaccination policies (i.e. requiring $\mathrm{HCW}$ vaccination or donning of mask during the entire influenza season) have the potential to improve $\mathrm{HCW}$ vaccination rates for influenza in particular. For example, in one British Columbia study, providing HCWs with the option of either receiving an influenza vaccination or requiring mask usage, independent of the presence of illness, during influenza season resulted in improved influenza vaccination rates, from $40 \%$ to $74 \%$ within one year (Ksienski, 2014).

According to recent studies, the majority of HCWs believe the influenza vaccine is both safe and effective (Maurer, Harris, Black, \& Euler, 2012). Some HCWs, however, maintain that vaccination mandates with consequences for noncompliance are too harsh (Winston, Wagner, \& Chan, 2014). Thus, some HCWs do not want to be required to abide by vaccination policies, even though the majority of HCWs also believe vaccinations to be safe. While HCW vaccination requirements may be uncomfortable to some $\mathrm{HCWs}$, it should be noted that there is 
also "no evidence to support concern that psychosocial harm from a mandatory

policy...alienate[s] staff [or] damage[s] morale" (Sullivan, Jacobson, \& Poland, 2009, p. 1497).

HCW resistance to mandatory vaccination policies was cited by clinic managers as a formidable barrier to enforcing a clinic vaccination policy in Utah family practice clinics. Clinic managers may be reluctant to enact and enforce vaccination policies for HCWs because they worry such policies infringe upon employees' personal rights and freedoms and may result in a lawsuit. Historically speaking, opponents to compulsory vaccination have filed court actions against institutions mandating vaccinations, usually citing a violation of personal rights and freedoms guaranteed by the $1^{\text {st }}, 4^{\text {th }}, 5^{\text {th }}, 10^{\text {th }}$, and $14^{\text {th }}$ Amendments. However, in cases filed by HCWs, court rulings confirm that while HCWs have inherent rights, they are also "required to submit to the limited intrusion of vaccination in order to protect both themselves and the patients in their care" (Stewart, 2009, p. 2021). Most states, in fact, recognize an institution's right to employ citizens as at-will employees, allowing termination for any reason except for race and disability status (Field, 2009). Thus, clinic managers are justified in decisions to implement and enforce HCW vaccination policies.

\section{Implications for Practice}

According to the American Association of Nurse Practitioners (2013), nurse practitioners have a responsibility to "promot[e]...optimal health," (para. 9) as well as to "promot[e] a safe environment" (para. 12). Additionally, the American Nurses Association (2015) recently updated their official statement on vaccines stating, "To protect the health of the public...all health care personnel... should be vaccinated according to current recommendations for immunizations by the CDC and Association for Professionals in Infection Control and Epidemiology" (para. 2). Ensuring all HCWs in the family practice clinic are adequately 
vaccinated promotes the optimal health of patients and HCWs by preventing the spread of infectious diseases. Therefore, supporting HCW vaccinations and vaccination policies within the family practice clinic setting simultaneously promotes a safer environment for all individuals.

Nurse practitioners are in a key position where they can influence clinic vaccination policies. In fact, nurse practitioners should evaluate the presence and effectiveness of the clinic's $\mathrm{HCW}$ vaccination policy and facilitate the creation of and adherence to vaccination policies by closely working with clinic managers. Additionally, nurse practitioners can be leaders and change agents by working with their county and state health departments to create state-wide policies that mirror the position statements from the American Nurses Association and the American Association of Nurse Practitioners.

\section{Study Limitations}

The convenience sample for this study was from one state and included the most densely populated counties in Utah. Therefore, the findings may not represent the entire population in the less populated counties in Utah or other family practice clinics located in the United States. Furthermore, because the sample only included family practice clinics, the findings may not represent vaccination policies in other specialties, such as pediatrics or oncology.

\section{Conclusion}

Rates of vaccine preventable diseases have steadily risen during the last 5 years. Thus far, the majority of research involving vaccination compliance has been conducted in the field of pediatrics, although the vaccination of adults is also an important aspect of community health. HCWs, in particular, are employed in environments where infectious diseases can be easily spread from person to person. In this study of family practice clinic vaccine policies, it is apparent that these clinics need to implement changes to create and maintain $\mathrm{HCW}$ vaccination 
policies. The presence of vaccination policies positively influences HCW compliance with the HCW vaccinations recommended by the ACIP. Nurse practitioners are in a key position where they should utilize their clinical expertise and patient advocacy skill to facilitate a safe environment for patients where the spread of infectious disease from HCW to patient is halted through vaccination policies. 


\section{References}

American Academy of Family Physicians. (2011). Family medicine facts. Retrieved from http://www.aafp.org/about/the-aafp/family-medicine-facts.html

American Association of Nurse Practitioners. (2013). Standards of practice for nurse practitioners. Retrieved from http://www.aanp.org/images/documents/publications/ standardsofpractice.pdf

American Nurses Association. (2015). American Nurses Association Position Statement on Immunizations. Retrieved from http://www.nursingworld.org/DocumentVault/PositionStatements/Practice/Immunizations.pdf

Centers for Disease Control and Prevention. (2009). Interim guidance for the use of masks to control influenza transmission. Retrieved from http://www.cdc.gov/flu/professionals/ infectioncontrol/maskguidance.htm

Centers for Disease Control and Prevention. (2011). Immunization of health-care personnel: Recommendations of the Advisory Committee on Immunization Practices (ACIP). Morbidity and Mortality Weekly Report, 60(RR07), 1-45.

Centers for Disease Control and Prevention. (2012). Adults need immunizations, too. Retrieved from http://www.cdc.gov/Features/AdultImmunizations/

Centers for Disease Control and Prevention. (2013a). Who should get vaccinated against influenza. Retrieved from http://www.cdc.gov/flu/protect/whoshouldvax.htm

Centers for Disease Control and Prevention. (2013b). Tetanus (lockjaw) vaccination. Retrieved from http://www.cdc.gov/Vaccines/vpd-vac/tetanus/default.htm Centers for Disease Control and Prevention. (2014a). Measles cases and outbreaks. Retrieved from http://www.cdc.gov/measles/cases-outbreaks.html 
Centers for Disease Control and Prevention. (2014b). Pertussis outbreak trends. Retrieved from http://www.cdc.gov/pertussis/outbreaks/trends.html

Centers for Disease Control and Prevention. (2014c). Immunization schedules for adults in easyto-read formats. Retrieved from http://www.cdc.gov/vaccines/schedules/easy-to$\mathrm{read} /$ adult.html

Centers for Disease Control and Prevention. (2015). Adult immunization schedules: United States, 2015. Retrieved from http://www.cdc.gov/vaccines/schedules/hcp/adult.html

Constable, C., Blank, N. R., \& Caplan, A. L. (2014). Rising rates of vaccine exemptions: Problems with current policy and more promising remedies. Vaccine, 32(16), 1793-1797.

Debolt, C., Tasslimi, A., Bardi, J., Leader, B. T., Hiatt, B., Washington State Department of Health., ...Meyer, S. (2012). Pertussis epidemic - Washington, 2012. Morbidity and Mortality Weekly Report, 61(28), 517-522.

Field, R. I. (2009). Mandatory vaccination of health care workers: Whose rights should come first? Pharmacy and Therapeutics, 24(11), 615-618.

Healthy People 2020. (2016). Immunization and infectious diseases. Retrieved from https://www.healthypeople.gov/2020/topics-objectives/topic/immunization-andinfectious-diseases/objectives

Henry J. Kaiser Family Foundation. (2014). The Utah health care landscape. Retrieved from http://kff.org/health-reform/fact-sheet/the-utah-health-care-landscape/

Immunization Action Coalition. (2014a). Ask the experts: Diseases and vaccines. Retrieved from http://www.immunize.org/askexperts/experts_mmr.asp

Immunization Action Coalition. (2014b). Healthcare personnel vaccination recommendations. Retrieved from www.immunize.org/catg.d/p2017.pdf 
Immunization Action Coalition. (2015). Influenza vaccination honor roll. Retrieved from http://www.immunize.org/honor-roll/influenza-mandates/honorees.asp

Infectious Diseases Society of America. (2014). 2013 IDSA clinical practice guideline for vaccination of the immunocompromised host. Retrieved from http://www.practiceupdate. com/news/4397

Infectious Diseases Society of America. (2015). Mandatory immunization of health care personnel against influenza and other infectious diseases. Retrieved from http://www.idsociety.org/HCW_Policy/

Infectious Diseases Society of America, Pediatric Infectious Diseases Society, \& The Society for Healthcare Epidemiology of America. (2013). IDSA, SHEA, and PIDS joint policy statement on mandatory immunization of health care personnel according to the ACIPrecommended vaccine schedule. Retrieved from http://www.idsociety.org/uploadedFiles/IDSA/Policy_and_Advocacy/Current_Topics_an d_Issues/Immunizations_and_Vaccines/Health_Care_Worker_Immunization/Statements/ IDSA_SHEA_PIDS\%20Policy\%20on\%20Mandatory\%20Immunization\%20of\%20HCP. pdf

Ksienski, D. S. (2014). Mandatory seasonal influenza vaccination or masking of British Columbia health care workers: Year 1. Canadian Journal of Public Health, 105(4), e312e316.

Lea, A. (2011, November). Vaccination education: Increasing vaccination rates through accurate information and primary care. Harvard College Global Health Review. Retrieved from http:/www.hcs.harvard.edu/hghr/online/vaccination-education/ 
Maurer, J., Harris, K. M., Black, C. L., \& Euler, G. L. (2012). Support for seasonal influenza vaccination requirements among US healthcare personnel. Infection Control and Hospital Epidemiology, 33(3), 213-221. doi:10.1086/664056

Ottenberg, A. L., Wu, J. T., Poland, G. A., Jacobson, R. M., Koenig, B. A., \& Tilburt, J. C. (2011). Vaccinating health care workers against influenza: The ethical and legal rationale for a mandate. American Journal of Public Health, 101(2), 212-216. doi:

10.2105/AJPH.2009.190751

Stewart, A. M. (2009). Mandatory vaccination of health care workers. New England Journal of Medicine, 361(21), 2015-2021. doi:10.1056/NEJMp0910151

Sullivan, S. J., Jacobson, R., \& Poland, G. A. (2009). Mandating influenza vaccination for healthcare workers. Expert Review of Vaccines, 8(11), 1469-1474. doi: 10.1586/ erv.09.118

Theodoridou, M. (2014). Professional and ethical responsibilities of health-care workers in regard to vaccinations. Vaccine, 32(38), 4866-4868. doi: 10.1016/j.vaccine.2014.05.068 United States Census Bureau. (2010). 2010 census data. Retrieved from http://www.census.gov/2010census/data/

United States Department of Health and Human Services. (2014). Seasonal flu. Retrieved from http://www.flu.gov/about_the_flu/seasonal/

Utah Department of Health. (2010a). Adult immunization recommendations. Retrieved from http://www.immunize-utah.org/information\%20for\%20the\%20public/adult\% 20immunization/adult\%20immunization\%20recommendations/index.html Utah Department of Health. (2010b). Adult immunization analysis. Retrieved from http://www.immunize-utah.org/statistics/utah\%20statistics/adult_immunization_ 
analysis.html

Winston, L., Wagner, S., \& Chan, S. (2014). Healthcare workers under a mandated H1N1 vaccination policy with employment termination penalty: A survey to assess employee perception. Vaccine, 32(37), 4786-4790. doi:10.1016/j.vaccine.2014.06.001

World Health Organization. (2015). Immunization. Retrieved from

http://www.who.int/topics/immunization/en/ 
Table 1

Demographics

\begin{tabular}{|c|c|c|c|}
\hline Result & Frequency $(\%)$ & Mean & SD \\
\hline \multicolumn{4}{|l|}{ Manager demographics $(n=79)$} \\
\hline Female & $59(74.7)$ & & \\
\hline Male & $20(25.3)$ & & \\
\hline Age & & 47 & 11.5 \\
\hline Years managing the clinic & & 11.2 & 8.1 \\
\hline \multicolumn{4}{|l|}{ Clinic demographics $(n=73)$} \\
\hline Suburban & $34(46.6)$ & & \\
\hline Urban & $32(43.8)$ & & \\
\hline Rural & $7(9.6)$ & & \\
\hline Number of patients per day* & & 113.7 & 153.9 \\
\hline
\end{tabular}

*Not including on-call or hospitalized patients 
Table 2

Required actions for unvaccinated and ill employees

$(\mathrm{n}=91)$

\begin{tabular}{lrr}
\hline Result & Frequency & Percent \\
\hline No additional requirements for employees & 22 & 24.2 \\
& & \\
Employees required to wear masks in the event of a fever, cough, or rash & 21 & 23.1 \\
Fever & 12 & 13.2 \\
Cough & 15 & 16.5 \\
Rash & 9 & 9.9 \\
& & \\
Employees restricted from patient care duties in the event of a fever, cough, & 15 & 16.5 \\
or rash & 11 & 12.1 \\
Fever & 9 & 9.9 \\
Cough & 6 & 6.6 \\
Rash & & 2 \\
Employees temporarily suspended in the event of a fever, cough, or rash & 2 & 2.2 \\
Fever & 2 & 2.2 \\
Cough & 2 & 2.2 \\
Rash & 2 & 2.2 \\
\hline
\end{tabular}


Table 3

Vaccine-related services for clinic employees $(\mathrm{n}=91)$

\begin{tabular}{lrr}
\hline Result & Frequency & Percent \\
\hline Free vaccines to employees & 53 & 58.2 \\
Education on the benefits/risks of vaccination & 36 & 39.6 \\
Regular tracking of employee vaccination rates & 27 & 29.7 \\
Employee vaccinations offered during nights and weekends & 20 & 22.0 \\
Vaccination rates reported to administrators/owners & 17 & 18.7 \\
Vaccinations offered during employee meetings & 11 & 12.1 \\
None of the above & 3 & 3.3 \\
Incentives for employee vaccination & 1 & 1.1 \\
Other & 1 & 1.1 \\
\hline
\end{tabular}


Table 4

Significant barriers to employee vaccination policy $(\mathrm{n}=36)$

\begin{tabular}{lrr}
\hline Result & Frequency & Percent \\
\hline Resistance to policy & 9 & 25 \\
Enforcement of policy & 9 & 25 \\
Violation of employee rights, privacy, freedom & 4 & 11 \\
Available resources for policy & 4 & 11 \\
Lack of understanding & 3 & 8.3 \\
Miscellaneous responses & 7 & 19 \\
\hline
\end{tabular}

